\title{
Executive attention and working memory in narcoleptic outpatients
}

\author{
Atenção executiva e memória de trabalho em pacientes com narcolepsia \\ Mirleny Moraes', Sueli Rossini², Rubens Reimão
}

\begin{abstract}
Objective: This pioneering study aimed to evaluate executive attention and working memory in Brazilian narcoleptic outpatients. Methods: Narcoleptic group: 19 treated narcoleptic outpatients (13 F; 6 M) (mean age=37.58; SD = 8.93); control group: 19 subjects (15 F; 4 M) (mean age =34.42; SD=12.31). Instruments: Epworth Sleepiness Scale - Brazilian Portuguese Version (ESS-BR), Victoria Stroop Test (VST), Trail Making Test (TMT) and Letter-Number Sequencing (LNS) of WAIS-III. Results: Significant difference at Excessive Daytime Sleepiness (EDS) $(p<0.001)$ and at working memory $(p=0.009)$ with worse results for narcoleptic patients. Patients were slower at VST-1 ( $p=0.002)$, VST-2 $(p=0.045)$ and at TMT-A $(p=0.016)$, TMT-B $(p=0.006)$ and B-A ( $p=0.024)$. Conclusion: Narcoleptic patients showed higher degrees of EDS, an impaired executive attention at a temporal level and lower performance in working memory when compared to normal controls.
\end{abstract}

Key words: sleep, narcolepsy, neuropsychology, attention, memory, working memory, executive function.

\section{RESUMO}

Objetivo: Este estudo pioneiro teve como objetivo avaliar a atenção executiva e a memória de trabalho em pacientes brasileiros com narcolepsia. Métodos: Grupo-estudo: 19 narcolépticos tratados (13 M; 6 H), com média de idade de 37,58 anos, DP=8,93; grupo-controle: 19 sujeitos (15 M; 4 H), com média de idade de 34,42 anos, DP=12,31. Utilizaram-se: a Escala de Sonolência de Epworth-BR, Victoria Stroop Test (VST), Trail Making Test (TMT) e Sequência de Números e Letras (SNL) da WAIS-III. Resultados: Houve diferença significativa nos graus de Sonolência Diurna Excessiva (SDE) ( $p<0,001)$ e na memória de trabalho ( $p=0,009)$, com piores resultados para o grupo-estudo. Do mesmo modo, verificaram-se tempos aumentados no grupo-estudo para execução do VST-1 ( $p=0,002)$, VST-2 $(p=0,045)$ e TMT-A ( $p=0,016)$, e TMT- $B$ $(p=0,006)$ e B-A ( $p=0,024)$. Conclusão: Os pacientes com narcolepsia apresentaram graus mais elevados de SDE, prejuízo na atenção executiva em nível temporal e desempenho inferior da memória de trabalho em relação aos sujeitos-controles.

Palavras-Chave: sono, narcolepsia, neuropsicologia, atenção, memória, memória de curto prazo, função executiva.

Narcolepsy is a chronic sleep disorder whose main symptoms are Excessive Daytime Sleepiness (EDS), characterized by the occurrence of Rapid Eye Movements (REM) and daytime sleep attacks, particularly in monotonous situations ${ }^{1}$. It may be associated to episodes of cataplexy (sudden reduction or loss of muscular tonus not accompanied by loss of consciousness), sleep paralysis (inability to move at falling asleep or waking up) and hypnagogic or hypnopompic hallucinations (onirical images that pervade the state of wakefulness) before falling asleep or at waking up, respectively. Lately, obesity has been included among the symptoms of narcolepsy².

The cause of narcolepsy was discovered in 1998 by two research groups working independently, who identified a mutation in the production of the neurotransmitter hypocretin I and II (orexins A and B) at the dorsolateral hypothalamus of patients with narcolepsy,3.4 The American Academy of Sleep Medicine (AASM) shows a prevalence from $0.02 \%$ to $0.18 \%$ for the American and west European populations, with the lowest index in Israel and a rise of prevalence in Japan (0.16 to 0.18$)^{1}$.

The symptomatology of the disease affects the patients' quality of life very considerably in the social ${ }^{5}$, psychological $^{6}$ and neuropsychological areas ${ }^{7-9}$. Patients complaints about memory failure are quite common', but research results announced so far are contradictory as to the true deficits on this function. Lefèvre, Barreto Filho and Reimão ${ }^{7}$ concluded for deficits in visual and auditory memory, whereas Naumann, Bellebaum and Daum ${ }^{10}$ reported modest memory impairments for narcoleptic patients related to verbal, but not to visual memory. In contrast, another researches ${ }^{9,11}$ showed no

${ }^{1}$ Neuropsychologist, Sleep Medicine Advanced Research Group, Division of Clinical Neurology, Hospital das Clínicas, University of São Paulo Medical School (FMUSP), São Paulo SP, Brazil;

${ }^{2}$ Psychologist, PhD, Sleep Medicine Advanced Research Group, Division of Clinical Neurology, Hospital das Clínicas, FMUSP, São Paulo SP, Brazil;

${ }^{3}$ Neurologist, MD, PhD, Sleep Medicine Advanced Research Group, Division of Clinical Neurology, Hospital das Clínicas, FMUSP, São Paulo SP, Brazil.

Correspondence: Rubens Reimão; Rua dos Bogarís 38; 04047-020 São Paulo SP - Brasil; E-mail: reimaorubensneuro@yahoo.com

Conflict of interest: There is no conflict of interest to declare.

Received 30 March 2011; Received in final form 20 October 2011; Accepted 27 October 2011 
memory deficits for narcoleptic patients with exception of working memory, even though a very recent neuropsychological investigation conducted by Delazer et al. ${ }^{12}$ yielded intact performance of narcoleptics in this kind of memory. Instead of memory problems, the studies have pointed to changes in the attentional capacity, such as poor performance on the more monotonous tests of auditory vigilance ${ }^{13}$, decrease in the level of alertness ${ }^{14}$, increase of latency of answers ${ }^{9,13}$ and deficits in the executive attention network which covers divided and flexible attention ${ }^{9,10,15}$. Moreover, functional neuroimaging and Event Related Potential (ERP) studies showed fatigue in the executive cortical network ${ }^{16}$, possible alterations in cognitive preattentive and attentive processing associated with altered functioning of the prefrontal $\operatorname{cortex}^{17}$ and electrophysiological aberrations in brain areas related to the executive attention network and the limbic system ${ }^{18}$.

Executive attention refers to the subject's capacity to cope with conflicts, errors and novelty that require further efforts of cognitive processing ${ }^{19}$. It requires control and coordination. Working memory is a system of temporary maintenance and information handling that allows complex reasoning performance, learning and understanding activities ${ }^{20}$. Executive attention and working memory are intrinsically related, the latter being considered an executive centre of attentional control ${ }^{20}$, whereas both of them are functionally coordinated by the prefrontal cortex. Furthermore, attention tests are multifactorial and overlap with working memory ${ }^{21}$ in terms of manipulation, updating and monitoring incoming information.

The objective of this research was to assess the executive attention and working memory in adult narcoleptic patients. We checked the degree of EDS and its correlation with performance on neuropsychological tests. IQ level was measured to control its influence on other cognitive functions.

\section{METHODS}

It is a prospective case-control study in which samples were selected by convenience. We evaluated 38 subjects, 28 females and 10 males, ranging from 19 and 55 years of age $(\mathrm{M}=36.00 ; \mathrm{SD}=10.73$ ), including 19 narcoleptic patients (narcoleptic group) and 19 subjects not suffering from narcolepsy (control group). All subjects were literate and most of them had completed or were enrolled in College.

Narcoleptic patients were recruited after clinical diagnosis by a neurologist expert in sleep disorders at the Neurology Department outpatient Clinic at the University of São Paulo Medical School (HC-FMUSP), based on standard clinical criteria ${ }^{1}$, polysomnographic and Multiple Sleep Latency Test (MSLT). Narcoleptic group comprised 19 subjects from 22 to 51 years old ( $\mathrm{M}=37.58 ; \mathrm{SD}=8.93), 13$ females and 6 males. All of them were clinically followed up at this clinic, and 16 of them had been taking medicines to control symptoms (stimulants and antidepressants). Excluded from this group were subjects reporting psychiatric or neurologic disorders with exception of depressive symptoms, that might entail further sleep disorders or who were taking psychiatric medication other than those prescribed to control EDS, representing none of the subjects of our initial sample. The control group comprised initially 23 volunteers or hospital staff of whom three were excluded because of their previous history of sleep disorder (insomnia) and one because of depression. We also considered any reported psychiatric or neurological disorder as exclusion criteria because of their consequences on sleep. Then, this sample totalized 19 subjects aged from 19 to 55 years ( $\mathrm{M}=34.42$; $\mathrm{SD}=12.31), 15$ females and 4 males. Visual or auditory disability preventing the performance on neuropsychological tests for either group also constituted an exclusion criterion.

The data were collected by the first author over three individually sessions of one hour and a half each. The order of tests was the same for all participants. During the first session, we conducted a semi-structured clinical interview, the filling in of questionnaire Brazil Economic Classification $(\mathrm{CEB})^{22}$, to characterize the subject's socioeconomic status. In the following sessions, we applied the Epworth Sleepiness Scale - Brazilian Portuguese Version (ESS-BR) ${ }^{23,24}$ to assess the presence of EDS, Raven's Progressive Matrices (RPM) ${ }^{25}$, as a criterion for intelligence level (IQ), Victoria Stroop Test (VST) ${ }^{21}$, Trail Making Test (TMT) ${ }^{21}$ and Letter-Number Sequencing (LNS) Subtest of Wechsler Adult Intelligence Scale 3rd ed. (WAIS-III) ${ }^{26,27}$ to evaluate executive attention and working memory. VST is one of the most widely used techniques to probe selective attention, processing speed, executive functions or response inhibition and cognitive flexibility ${ }^{21}$. It is formed of three parts: the first one requires the subject to name the colors of 24 rectangles; the second, the colors of various words; and the third, colors of written words not matching to the meaning of the words themselves, causing the Stroop effect (interference of color in the word) which tends to bring about slowing of performance and can be calculated by ratio or by the difference between the third and first part of the test ${ }^{21}$. As a measurement for attention, lies at the top of the rank, and as a measurement of executive functioning (set-shifting, cognitive flexibility, switching/inhibition), it is the fourth mostly used. It is made up of two trails (A and B), which require visual tracking and speeded performance, although Trail B is considered as a purer measure of divided and flexible attention. Both VST and TMT scoring are expressed in terms of time in seconds required for complete each part of the test. The instructions for administering the tests were based on Strauss, Sherman and Spreen ${ }^{21}$. The LNS subtest, from WAIS-III, assesses updating manipulation and switching/inhibition of information from working memory through a mnemonic retention of alternating sequences 
of numbers and letters and their subsequent recalling in an organized and joint form (crescent and alphabetical orders). Administering followed the rules in the Manual Scale ${ }^{26,27}$.

The statistical analysis employed the software Statistical Package for the Social Sciences for Personal Computer for Windows (SPSS) ${ }^{28}$. For comparing numerical measures between the groups, Mann-Whitney non-parametric tests were used, and for checking the association of categorized measures, chi-square and/or Fisher's exact test were applied. For all statistical measures, it was adopted the significance level of $5 \%$.

\section{Ethics}

This research is part of a larger project of the authors on narcolepsy and was duly approved by the Hospital das Clínicas' Ethics Committee, a branch of University of São Paulo Medical School (FMUSP), in June 2007, under Research Protocol \#0455/07. All patients and controls signed the Informed Consent Term, in accordance with the ethical standards set up by the National Health Council (Resolution 01 of June 13, 1988) on a proper form of HC-FMUSP.

\section{RESULTS}

\section{Sociodemographic variables}

The comparative statistical analysis of narcoleptic and control groups showed they were homogeneous in the sociodemographic variables: aging, gender, marital status, years of schooling and social economic status (Table 1).

\section{Excessive Daytime Sleepiness}

EDS presence was confirmed in the patients of narcoleptic group, accounting for a high rate of statistical significance $(\mathrm{p}<0.001)$ when matched to the control group subjects. It is directly correlated with the performance time in the test of executive attention (VST-2) $(\mathrm{p}=0.041 ; \mathrm{r}=0.473)$.

\section{IQ level}

Mann-Whitney test showed no significant statistical difference between the groups $(\mathrm{p}=0.465)$.

\section{Executive attention}

The results of executive attention assessed by the VST pointed out that the narcoleptic patients were significantly slower than those of control group when performing Parts 1 and 2, although not in Part 3 (Table 2). The amount of errors was not different between groups (VST-1 $\mathrm{p}=0.553$; VST-2 $\mathrm{p}=0.152 ;$ VST $-3 \mathrm{p}=0.603)$. Mann-Whitney statistical test showed no significant difference in the groups regarding the interference effect (Part 3 minus Part 1; $\mathrm{p}=0.311$ ). During the test, three narcoleptic patients made physiological complaints: dizziness, sleepiness and uncontrollable laughter. The analysis of results found in the TMT-A and TMT-B showed that subjects in the narcoleptic group were slower than the control group in both parts, but especially in Trail B, at which the mean time performance was nearly twice the mean time employed by the control group (Table 2). We took the ratio and the difference between Trails B and A to check possible deficits of divided and alternating attention, since this operation excludes speed processing from the assessment,

Table 1. Sample characteristics: sociodemographic variables.

\begin{tabular}{|c|c|c|c|c|c|c|c|c|}
\hline \multirow{3}{*}{$\begin{array}{l}\text { Variables } \\
\text { Aging }\end{array}$} & \multirow{3}{*}{$\begin{array}{l}\text { Categories } \\
\text { Mean }\end{array}$} & \multicolumn{2}{|c|}{$\begin{array}{l}\text { Narcoleptic group } \\
\qquad(n=19)\end{array}$} & \multicolumn{2}{|c|}{$\begin{array}{l}\text { Control group } \\
\qquad(n=19)\end{array}$} & \multicolumn{2}{|c|}{$\begin{array}{c}\text { Total } \\
(n=38)\end{array}$} & \multirow{3}{*}{$\begin{array}{r}\text { p-value } \\
0.342\end{array}$} \\
\hline & & \multicolumn{2}{|c|}{37.58} & \multicolumn{2}{|c|}{34.42} & \multicolumn{2}{|c|}{36.00} & \\
\hline & & $\mathrm{N}$ & $\%$ & $\mathrm{~N}$ & $\%$ & $\mathrm{~N}$ & $\%$ & \\
\hline \multirow[t]{2}{*}{ Gender* } & $M$ & 6 & 31.6 & 4 & 21.1 & 10 & 26.3 & \multirow{2}{*}{0.714} \\
\hline & $\mathrm{F}$ & 13 & 68.4 & 15 & 78.9 & 28 & 73.7 & \\
\hline \multirow[t]{5}{*}{ Marital status** } & Married & 8 & 42.1 & 5 & 26.3 & 13 & 34.2 & \multirow{5}{*}{0.645} \\
\hline & Divorced & 1 & 5.3 & 1 & 5.3 & 2 & 5.3 & \\
\hline & Separated & 1 & 5.3 & 0 & 0 & 1 & 2.6 & \\
\hline & Single & 8 & 42.1 & 11 & 57.9 & 19 & 50.0 & \\
\hline & Widow/er & 1 & 5.3 & 2 & 10.5 & 3 & 7.9 & \\
\hline \multirow[t]{5}{*}{ Schooling** } & Unfinished elementary education & 2 & 10.5 & 1 & 5.3 & 3 & 7.9 & \multirow{5}{*}{0.854} \\
\hline & Finished elementary education & 1 & 5.3 & 2 & 10.5 & 3 & 7.9 & \\
\hline & Finished secondary education & 5 & 26.3 & 3 & 15.8 & 8 & 21.1 & \\
\hline & Unfinished College & 4 & 21.1 & 5 & 26.3 & 9 & 23.7 & \\
\hline & $\begin{array}{l}\text { Finished } \\
\text { College }\end{array}$ & 7 & 36.8 & 8 & 42.1 & 15 & 39.5 & \\
\hline \multirow{4}{*}{$\begin{array}{l}\text { Social } \\
\text { economic status** }\end{array}$} & A2 & 3 & 15.8 & 2 & 10.5 & 5 & 13.2 & \multirow{4}{*}{0.588} \\
\hline & B1 & 4 & 21.0 & 4 & 21.0 & 8 & 21.0 & \\
\hline & B2 & 4 & 21.0 & 3 & 15.8 & 7 & 18.4 & \\
\hline & C & 8 & 42.2 & 10 & 52.7 & 18 & 47.4 & \\
\hline
\end{tabular}

*Fisher's Exact Test; **Chi-square; M: masculine; F: feminine. 
prevailling the purer measure of these types of attention. Ratio B/A did not show difference between the groups, but the subtraction B-A pointed out a significant statistical difference between the groups ( $p=0.024)$, with worse results for the narcoleptic patients. The statistical analysis of errors in both trails pointed to no significant difference between the groups (TMT-1 p=0.553; TMT-2 p=0.201).

\section{Working memory}

After statistical data, LNS results showed a significant difference between the groups $(p=0.009)$, with a lower performance by the clinical group at recalling elements (Table 3 ).

\section{DISCUSSION}

The analysis of executive attention employed specifically by VST-2, VST-3 and TMT-B showed significant slowing performance for the narcoleptic patients, whereas results in LNS as measures of working memory pointed to a difference between groups with lower results for narcoleptic group compared to the control group. The three tasks require the maintenance of two trains of thought from different categories at the same time: switching between them, frequent updating and monitoring, cognitive flexibility, inhibitory control, divided and alternating attention, monitoring, cognitive flexibility, inhibitory control, divided and alternating attention.

Based on these results, we could argue for difficulty in cognitive flexibility, but there were neither significant perseverative errors nor statistical significant difference between groups in VST or in TMT, which would also explain that there were inhibitory control and cognitive flexibility by all the subjects. However, the slowing performance of narcoleptic group

Table 2. Performance time for VST (Parts 1, 2, 3) and TMT-A and TMT-B.

\begin{tabular}{lccccc} 
& \multicolumn{2}{c}{$\begin{array}{c}\text { Narcoleptic group } \\
(\mathrm{n}=19)\end{array}$} & \multicolumn{2}{c}{$\begin{array}{c}\text { Control group } \\
(\mathrm{n}=19)\end{array}$} & \\
\cline { 2 - 5 } Tests & \multicolumn{2}{c}{ Performance time } & \multicolumn{2}{c}{ Performance time } & p-value \\
\cline { 2 - 5 } & $\mathrm{M}$ & $\mathrm{SD}$ & $\mathrm{M}$ & $\mathrm{SD}$ & \\
\hline VST-1 & 20.65 & 7.84 & 14.33 & 3.38 & 0.002 \\
VST-2 & 23.04 & 10.48 & 16.96 & 3.28 & 0.045 \\
VST-3 & 33.00 & 13.3 & 27.11 & 9.15 & 0.175 \\
TMT-A & 44.84 & 19.56 & 30.82 & 13.93 & 0.016 \\
TMT-B & 123.15 & 85.16 & 70.01 & 32.20 & 0.006 \\
\hline
\end{tabular}

Mann-Whitney; *In seconds; N: number of patients; VST:Victoria Stroop Test; TMT: Trail Making Test; M: mean; SD: standard deviation.

Table 3. Letter-Number Sequencing of WAIS-III results.

\begin{tabular}{lccccccc} 
Groups & N & Min & Max & M & Med & SD & p-value \\
\hline Narcoleptic & 19 & 1 & 18 & 8.58 & 8.00 & 3.49 & \\
Control & 19 & 5 & 14 & 10.74 & 11.00 & 2.33 & 0.009 \\
\hline
\end{tabular}

Mann-Whitney; N: number of patients; Min: minimum; Max: maximum; M: mean; Med: median;SD: standard deviation. reflected a time-consuming process for resolving response competition and/or for updating and monitoring (working memory functions). Patients needed more time to perform more complex functions of executive attentional control: to divide and to switch between different categories of stimuli. However, it struck us that in VST-3, in which stimuli are more discordant and concurrent, the stroop effect did not occur: the time and the quality of performance were similar in the two groups.

Considering the slowing performance in VST-1 and TMT-A, which recruit basic functions of perception, selection, global attention and still the presence of EDS and physiological complaint of those narcoleptic patients, we hypothesize that more global factors were influencing these results, as the mental efforts of narcoleptic patients at processing stimuli, which sometimes were reflected on physiological changes, perhaps a dysfunctional executive attention control and the increase in the vigilance level to overcome the biggest challenge in Part 3, making them recover the speed without errors.

In the study carried out by Naumann et al. ${ }^{10}$, which assessed a variety of cognitive functions, the analysis of divided attention through visual and acoustic task - implemented in parallel - and in which subjects had to press a bar in order to switch between stimuli recorded that patients and controls showed no difference as to errors, but narcoleptics were significantly slower to detect target stimuli. Rieger et al. ${ }^{9}$ found that narcoleptic patients (treated or not) were slower than controls in the dual condition of divided attention, with slower and more variable reaction times for visual than acoustic stimuli.

Our results converge with those of other researches pointing to deficits of divided attention ${ }^{9,15}$ or to reports of great mental effort to take tests with this type of demand in narcoleptic patients, treated or not ${ }^{8,13}$.

In the attention and speed aspects, several studies indicate a higher reaction time for narcoleptic patients when matched to samples of people at large $e^{9,10,13}$.

The attempt for accuracy by narcoleptics resulted in slowness. If this was a compensatory strategy aiming at a fine performance, the relevant question to ask is: what would be its impact on everyday activities? Here is the core of the effectiveness of this sort of behavior.

Studies bring evidence that differences in VST trials scores correlate to differences in TMT trails. Moreover, VST-2, VST-3 and TMT hold factors of working memory ${ }^{21}$ as for TMT, two sequences of stimuli of different categories must be kept on line and manipulated. Some researchers theorize that the working memory contributes to the stroop interference in two ways: either by reflecting a failure to maintain the goal of the task - to ignore the word dimension - or in the time employed to solve a conflict among answers ${ }^{21}$.

Considering Baddeley et al'.s ${ }^{20}$ theory that the working memory is a system controlled by a central executive, which 
is an attentional controller, it makes sense that the difference between groups in all three instruments, except for VST-3, has been similar. The conflict generated by competing demands would lead to an overload in the narcoleptic patients' attentional network, bringing about slowness of performance.

Thomas's research ${ }^{16}$ with RMf pointed that there is fatigue in the narcoleptic patients' executive cortical network. Working memory, the required component in the task, should make subjects keep and manipulate a sequence of letters and sustain attention. All subjects reported a subjective decline of alertness during the evaluation.

A reduction worth of note in the activation of the areas involved in the executive functions and activation in areas generally not considered a part of this network took place. According to the author, those results reflect the patients' cognitive effort to sustain their performance, and such effort activates secondary areas of the brain that are nonetheless functionally connected. His conclusion is that amphetamines increase the activation in the executive network of the dorsolateral prefrontal cortex, while modafinila does it only when there is a sleep deprivation.

Rieger et al. ${ }^{9}$ also concluded for deficits in the executive attentional network and Naumann et al. ${ }^{17}$ interpreted the changes in the narcoleptic patients' Event-related Potentials (ERPs) as possible alterations in pre-attentive and cognitive attentive processes with change in the mechanism of prefrontal cortex. The results of ERPs electromagnetic topographies (ERP-LORETA) found by Saletu et al. ${ }^{18}$ showed a prolonged information processing, decreased energetic resources for cognitive processing and electrophysiological aberrations in brain areas related to the executive attention network and to the limbic system, which contributes to deterioration in mental performance and mood at the behavioral level.

Results of significant statistical difference in EDS between the groups were expected beforehand owing to the symptoms of the disease. Although most narcoleptic patients were treated and the medication was reported as tools for soothing EDS and improving the quality of attention and memory, EDS never failed to be present in the daily life of subjects, in higher or lower degree, as its variation in the ESS-BR ( from 9 to 24 points) clearly indicates.
One of our hypotheses at the beginning was to find more solid associations, and in larger numbers, between the EDS variables and the performance of neurocognitive tests for narcoleptic patients, but, in spite of that, the EDS degree correlated in a directly way with the performance time in the test of executive attention (VST-2), which means higher degrees of sleepiness associated with slowness. The slowing of narcoleptics related to those in control group in tasks requiring higher attentional control may have taken place due to factors associated to EDS, and the dejection in performing daily activities reported by most patients and the high incidence of depressive symptoms may have contributed to those results.

We concluded that the narcoleptic patients, in our sample, did not show intellectual deficits. However, the coordination and attentional control exerted by executive attention and working memory were impaired as to the temporal order in this group in the face of the need to split and switching attentional resources. Narcoleptic patients had achieved a performance similar to that of controls, the difference consisting in the slowing of performing tasks.

Electrophysiological brain alterations and the degree of EDS - the chief symptom of the disorder - may concur negatively in the performance of tasks concerning executive attention and working memory.

Of course, our research has limitations. One was the small sample size, especially of the control group. Another one is that it may seem that few instruments were used for the evaluation of executive attention and working memory. In fact, it was, but this study is part of a larger project in which ten neuropsychological tests were used to evaluate other functions (with many derived measures) and three other scales. In general, we could confirm the results of other authors on some dysfunction in the latter functions.

Except for two, all other patients were under medication and this important and necessary factor certainly contributed to our results. In addition, we agree with Aguirre et al. ${ }^{8}$ about patients being able to offset the effects of sleepiness due to the aspect of motivating tasks and the artificial laboratory environment leading to inaccurate measures of patients psychological functioning in relation to their daily life with continuous and simultaneous stimulation of multiple modalities.

\section{References}

\footnotetext{
1. American Academy of Sleep Medicine. International classification of sleep disorders: Diagnostic and coding manual. 2nd ed. Westchester, Illinois: American Academy of Sleep Medicine; 2005.

2. Guilleminault C. Avanços na fisiopatologia e tratamento da narcolepsia. In: XXIII Congresso Brasileiro de Neurologia: avanço no tratamento da sonolência excessiva; 2008. Belém [em CD-ROM]. Bauru: Unimagem Produções Audiovisuais Ltda.; 2008.

3. De Lecea L, Kilduff T, Peyron C, et al. The hypocretins: hypothalamus-

specific peptides with neuroexcitatory activity. Proc Natl Acad Sci USA 1998;95:322-327.

4. Sakurai T, Amemiya A, Ishii M, et al. Orexins and orexin receptors: a family of hypothalamic neuropeptides and $G$ protein-coupled receptors that regulate feeding behavior. Cell 1998;92:573-585.

5. Rovere R, Rossini S, Reimão R. Quality of life in patients with narcolepsy: a WHOQOL-bref study. Arq Neuropsiquiatr 2008;66:163-167.
} 
6. Rovere H, Rossini S, Alcântara C, et al. Avanços na qualidade de vida em portadores de narcolepsia. Mudanças - Psicologia da Saúde 2006;14:74-78.

7. Lefèvre BH, Barreto Filho MGM, Reimão R. Narcolepsia: avaliação neuropsicológica. Neurobiologia 1990:53:25-32.

8. Aguirre M, Broughton R, Stuss D. Does memory impairment exist in narcolepsy-cataplexy? J Clin Exp Neuropsychol 1985;7:14-24.

9. Rieger M, Mayer G, Gauggel S. Attention deficits in patients with narcolepsy. Sleep 2003;26:36-43.

10. Naumann A, Bellebaum C, Daum I. Cognitive deficits in narcolepsy. J Sleep Res 2006;15:329-338.

11. Ha KS, Yoo HK, Lyoo IK, Jeong DU. Computerized assessment of cognitive impairment in narcoleptic patients. Acta Neurol Scand 2007;116:312-316.

12. Delazer M, Högl B, Zamarian L, et al. Executive functions, information sampling, and decision making in narcolepsy with cataplexy. Neuropsychology 2011;25:477-487.

13. Valley $V$, Broughton R. Daytime performance deficits and physiological vigilance in untreated patients with narcolepsy-cataplexy compared to controls. Rev Electroencephalogr Neurophysiol Clin 1981;11:133-139.

14. Kotterba S, Mueller N, Leidag M, et al. Comparison of driving simulator performance and neuropsychological testing in narcolepsy. Clin Neurol Neurosurg 2004;106:275-279.

15. Hood B, Bruck D. Sleepiness and performance in narcolepsy. J Sleep Res 1996;5:128-134.

16. Thomas R. Fatigue in the executive cortical network demonstrated in narcoleptics using functional magnetic resonance imaging: a preliminary study. Sleep Med 2005;6:399-406.

17. Naumann A, Bierbrauer J, Przuntek H, Daum I. Attentive and preattentive processing in narcolepsy as revealed by event-related potentials (ERPS). Neuroreport 2001;12:2807-2811.

18. Saletu M, Anderer P, Saletu-Zyhlarz G, Mandl M, Zeitlhofer J, Saletu B.
Event-related-potential low-resolution brain electromagnetic tomography (ERP-LORETA) suggests decreased energetic resources for cognitive processing in narcolepsy. Clin Neurophysiol 2008;119:1782-1794.

19. Fernandez-Duque D, Posner MI. Brain imaging of attentional networks in normal and pathological states. J Clin Exp Neuropsychol 2001;23:74-93.

20. Baddeley A, Eysenck M, Anderson M. Memory. Hove, East Sussex: Psychology Press; 2009.

21. Strauss E, Sherman EMS, Spreen O. A compendium of neuropsychological tests: administration, norms and commentary. 3nd ed. New York: Oxford University Press; 2006.

22. Critério de classificação econômica Brasil [on-line]. Associação Nacional de Empresas de Pesquisa; CEP; 2000. Available at http:// www.abep.org/codigosguias/ABEP CCEB.pdf.

23. Johns MW. A new method for measuring daytime sleepiness: the Epworth Sleepiness Scale. Sleepiness 1991;14:540-545.

24. Bertolazi A. Tradução, adaptação cultural e validação de dois instrumentos de avaliação do sono: Escala de Sonolência de Epworth e Índice de Qualidade de Sono de Pittsburgh. [dissertação]. Porto Alegre: Universidade Federal do Rio Grande do Sul; 2008.

25. Raven JC. Standard Progressive Matrices Sets A-E. Oxford: Oxford Psychologists Press: manual. 3a ed. Tradução e Adaptação de Francisco Campos. Rio de Janeiro: Centro Editor de Psicologia Aplicada Ltda; 2003.

26. Wechsler D. Wechsler Adult Intelligence Scale. 3rd ed. San Antonio, TX: The Psychological Corporation; 1997.

27. Nascimento EM. Adaptação e validação do WAIS-III para um contexto brasileiro [Tese de Doutorado]. Brasília: Instituto de Psicologia da Universidade de Brasília; 2000.

28. SPSS - Statistical Package for Social Sciences for Personal Computer for Windows. Version 13.0. United States of America: SPSS Inc. 